University of Nebraska - Lincoln

DigitalCommons@University of Nebraska - Lincoln

1951

\title{
The Sedimentation Rate of Potato Yellow-Dwarf Virus
}

M. K. Brakke

National Institutes of Health

L. M. Black

National Institutes of Health

Ralph W. G. Wyckoff

National Institutes of Health

Follow this and additional works at: https://digitalcommons.unl.edu/plantpathpapers

Part of the Plant Pathology Commons

Brakke, M. K.; Black, L. M.; and Wyckoff, Ralph W. G., "The Sedimentation Rate of Potato Yellow-Dwarf Virus" (1951). Papers in Plant Pathology. 160.

https://digitalcommons.unl.edu/plantpathpapers/160

This Article is brought to you for free and open access by the Plant Pathology Department at DigitalCommons@University of Nebraska - Lincoln. It has been accepted for inclusion in Papers in Plant Pathology by an authorized administrator of DigitalCommons@University of Nebraska - Lincoln. 


\title{
THE SEDIMENTATION RATE OF POTATO YELLOW-DWARF VIRUS ${ }^{1}$
}

\author{
M. K. Brakke, L. M. Black, and Ralph W. G. Wyckoff
}

BLACK et al. (1948) have published electron micrographs of bodies believed to represent the New York variety of potato yellow-dwarf virus (Aureogenus vastans ( $\mathrm{H})$ Black) (Holmes 1948). The photographs showed bodies in several different extracts of infected plants of Nicotiana rustica L., but not in corresponding preparations from healthy plants. Similar bodies were found in concentrates from plants infected with the New Jersey variety of the virus (var. agalliae Black). These bodies were larger than, and of a different character from, those of plant viruses hitherto examined in the electron microscope. The present study was undertaken to obtain evidence that might more closely identify these bodies with the virus, to ascertain if the sedimentation rate of the virus activity was consistent with the size of the bodies, and to determine the sedimentation constant of this active virus in order to use it in further attempts at purification. At the same time, the experiments were designed and carried out in the expectation that they might serve as a guide to later work with other plant viruses with long incubation periods in their leafhopper vectors, particularly the wound-tumor virus (Aureogenus magnivena Black). Potato yellowdwarf virus is the easiest member of this group to work with because it is the only one that has been readily transmitted mechanically from plant to plant. It produces many primary lesions on inoculated susceptible leaves of $N$. rustica and, therefore, unlike the other viruses of the group, can be subjected to a convenient and roughly quantitative bioassay.

Pure preparations of this virus have not been made. Because of its instability, centrifugation at or near $0^{\circ} \mathrm{C}$. is the only technique which has given promising results in the preparation of concentrates. However, due to the many impurities in unfrozen plant juice that are nearly the same size as the virus, and due to the progressive denaturation of the virus even at low temperatures, it has not proved worthwhile to make more than two cycles of centrifugation. Because concentrates prepared in this manner are relatively impure, it was desirable to use a technique whereby infectivity combined with electron microscopy could be used to follow the sedimentation rate of the virus. For this purpose, a capillary tube method using horizontal centrifugation appeared preferable, from both theoretical and practical viewpoints, to one using angle centrifugation.

Centrifugation in capillary tubes has been used by Elford (1936) to determine the sedimentation rates of a number of viruses and bacteria. McIn-

1Received for publication June 26, 1950.

This work was supported, in part by a Grant-in-Aid from the American Cancer Society upon recommendation of the Committee on Growth of the National Research Council. tosh and Selbie (1937) employed somewhat larger tubes $(2.0-0.5 \mathrm{~cm}$.) and a high speed air driven centrifuge for the same purpose. These workers measured the percentage of infectivity left in a given portion of the supernatant and calculated particle size directly from these data, after making assumptions as to density and shape. They did not express the results as sedimentation constants.

In the present work a capillary tube of $2 \mathrm{~mm}$. inside diameter and several centimeters long was centrifuged in swinging cups in an International size 1-SB centrifuge until the virus had sedimented approximately $2 \mathrm{~cm}$. The use of small diameter tubes reduced the danger of mixing during centrifugation and subsequent manipulations. Allowing the virus to sediment a relatively great distance considerably increased the accuracy of a sedimentation constant measurement for any fixed error involved in removing the sample. After centrifugation, samples were taken at various depths and assayed for infectivity. This was preferred to assaying for the percentage of virus left in a given proportion of the supernatant, since it obviated the necessity for a quantitative assay. In practice, the virus was found to be absent in all samples removed above and present in all samples removed below a certain point. Expressing the results thus obtained as a sedimentation constant has the advantage over calculations of a particle size inasmuch as such a constant characterizes each type of particle and requires no assumptions as to density and shape of the particle concerned.

Preliminary experiments (Brakke et al., 1950) showed a boundary visible to the naked eye in centrifuged capillary tubes containing concentrates from diseased plants whereas no similar boundary was observed in tubes containing corresponding concentrates from healthy plants. ${ }^{2}$ This boundary was visible because of a sudden increase, over the distance of a few tenths of a millimeter, in the scattered light. Samples removed from below this boundary were infective while those removed from above it were not, indicating that the virus was associated with the boundary.

MATERIALS AND METHODS.- $N$. rustica plants infected with New York potato yellow-dwarf were used as a source of the virus. Preparations of the virus were made by differential centrifugation using a refrigerated Servall SS-2 vacuum-type centrifuge which had an angle head 12 in. in diameter. Times and speeds of centrifugation were based on preliminary studies of the sedimentation of the infectivity in angle head centrifuges (Black, 1950). All preparative work was done in a cold room kept between $0^{\circ}$ and $3^{\circ} \mathrm{C}$., the following procedure being

2In 2-3 week-old preparations from healthy or diseased plants several boundaries were observed. The cause of these boundaries is unknown; none of them coincided with the boundary mentioned above. 
used in most cases. Thoroughly infected leaves were collected, washed with tap water and stored overnight in the cold room. They were blended for $3 \mathrm{~min}$. in a Waring blendor ${ }^{3}$ with $100 \mathrm{ml}$. of solvent I $(0.05 \mathrm{M}$ sucrose, $0.15 \mathrm{M} \mathrm{NaCl}$, and 0.01 $\mathrm{M}$ neutral potassium phosphate buffer) and $4 \mathrm{~g}$. of $\mathrm{K}_{2} \mathrm{HPO}_{4}$ per $100 \mathrm{~g}$. of leaves. This gave a nearly neutral extract which was squeezed through cheesecloth. The virus was concentrated by two cycles of differential centrifugation, clarification being carried out at 10,000 r.p.m. for $10 \mathrm{~min}$. and the virus sedimented down at 13,000 r.p.m. for $1 \mathrm{hr}$. After being thrown down the first time the virus was taken up in half the original volume of solvent I. The last precipitate was taken up in a small amount of solvent II $(0.15 \mathrm{M} \mathrm{NaCl}, 0.01 \mathrm{M}$ neutral potassium phosphate buffer) which was the suspending medium used for sedimentation rate experiments. The green color was not completely removed from any of the preparations. The preparation of virus concentrates and the measurements of sedimentation rates could be carried out in 2 days. However, sometimes a week was allowed to elapse before the sedimentation rates were determined. Similar sedimentation constants were obtained in all cases but electron micrographs of preparations a week old showed less contaminating material. Concentrates from healthy $N$. rustica plants were always prepared and investigated at the same time as those from diseased plants.

Infectivity assays were carried out by dusting $N$. rustica leaves of the proper age (Black, 1938) with carborundum ( 500 mesh) and then rubbing the leaves with a cheesecloth pad soaked in the extract to be tested. Comparisons of infectivity in different extracts were made by inoculating opposite half leaves.

The $2 \mathrm{~mm}$. capillary tubes were held in place in a water-filled centrifuge cup by a $3 \mathrm{~mm}$. section of a one-hole rubber stopper at the bottom and by a cork with a hole in its center at the top. Best results were obtained with one tube per cup. The centrifuge was run in the cold room for 4-6 hr., the speed being noted at hourly intervals. Other measurements were made after the centrifuge had stopped. The temperature of the water surrounding the tubes was determined, separate experiments having shown that this temperature reached a certain level in $15 \mathrm{~min}$. and then remained constant. The heights of the bottom of the meniscus and of any visible boundaries were measured. Samples were removed from various depths with a fine hooked capillary (fig. 1) and used for infectivity tests and electron microscope mounts. Fig. I also shows examples of the capillary tubes that were used, one tube showing a boundary obtained after centrifuging a virus preparation and the other a concentrate from healthy plants under similar conditions.

${ }^{3}$ Tests showed that extracts obtained from a Waring blendor were as infective as those obtained by thorough maceration of the leaves in a mortar and pestle.

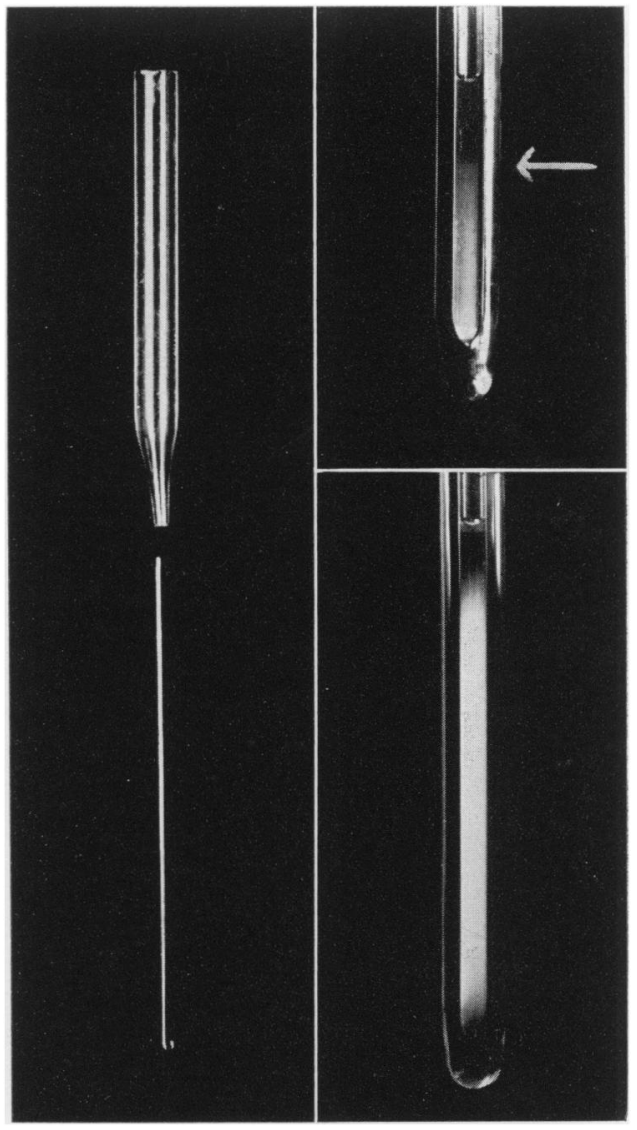

Fig. 1. Capillary tubes used for determination of sedimentation rates. The lower tube on the right shows a concentrate from healthy $N$. rustica after centrifugation; the upper tube on the right shows a concentrate from yellowdwarf plants after centrifugation. The boundary marked with an arrow is due to the virus. The capillary hook on the left is of the type used for removing samples after centrifugation.

Details of one sedimentation rate experiment will be given to show typical results. A virus concentrate was prepared from $215 \mathrm{~g}$. of $N$. rustica leaves to have a final volume of $2.8 \mathrm{ml}$. with $0.8 \mathrm{mg}$. N per $\mathrm{ml}$. A sample in a $2 \mathrm{~mm}$. tube was centrifuged $6 \mathrm{hr}$. at 3125 r.p.m. with a final temperature of $9^{\circ} \mathrm{C}$. A boundary was visible $13.55 \mathrm{~cm}$. from the center of rotation. One sample equal to $5 \mathrm{~mm}$. of liquid in the tube $(c a 15 \mu \mathrm{l}$.) was removed at 13.35 $\mathrm{cm}$. from the center of rotation and a second at $14.05 \mathrm{~cm}$. After dilution to $0.5 \mathrm{ml}$. with solvent II, $0.1 \mathrm{ml}$. was removed from each for electron microscopy while the remaining $0.4 \mathrm{ml}$. was diluted to $1 \mathrm{ml}$. with the same solvent and used for infectivity assay. Two leaves on different $N$. rustica plants were inoculated, the upper sample being placed on one-half of each leaf and the lower sample on the other half. The half leaves inoculated with the upper sample developed no lesions, while one of those inoculated with the lower sample de- 
veloped 297 lesions and the other more than 600 . Electron micrographs of the upper sample contained none of the characteristic bodies while those from the lower one contained many.

For calculation of the sedimentation constant from such data (Svedberg and Pedersen, 1940), the formula used was

$$
\mathrm{S}_{20}^{\prime}=\frac{2.303 \eta\left(\rho_{\mathrm{v}}-\rho_{\mathrm{o}}\right)}{\mathrm{t} \omega^{2} \eta_{\mathrm{o}}\left(\rho_{\mathrm{v}}-\rho\right)} \log \frac{\mathrm{x}_{2}}{\mathrm{x}_{1}}
$$

where $\mathrm{S}_{20}^{\prime}$ is the apparent sedimentation constant in water at $20^{\circ} \mathrm{C}$., $\eta$ is the viscosity of the solvent at the temperature of the experiment, $\eta_{0}$ is the viscosity of water at $20^{\circ} \mathrm{C} ., \rho_{v}$ is the anhydrous density of the virus, $\rho_{0}$ is the density of water at $20^{\circ} \mathrm{C}$., $\rho$ is the density of the solvent at the temperature of the experiment, $t$ is the time in seconds during which the virus was centrifuged at an angular velocity of $\omega$ radians per second, $\mathrm{x}_{2}$ is the distance of the virus from the center of rotation at the end of the centrifugation, and $x_{1}$ is the distance of the top of the solution from the center of rotation. $\mathrm{S}_{20}^{\prime}$ is the apparent sedimentation constant, for no correction has as yet been applied for the interference of the impurities of the preparation with the sedimentation of the virus. For the purposes of these calculations, $\rho_{\mathrm{V}}$ was assumed to be 1.3, an assumption based on the known density of proteins and other viruses. Because of the small difference between $\rho$ and $\rho_{0}$, a large error in $\rho_{\mathrm{v}}$ gives rise to only a small error in $\mathrm{S}_{20}^{\prime}$. A correction of $0.3 \mathrm{~mm} .{ }^{4}$ was always made for the flattening of the meniscus during centrifugation. The viscosity and density of the solvent were determined experimentally at the temperature of the centrifugation. In the present example, $\mathrm{x}_{1}$ was $11.72 \mathrm{~cm}$. Substitution of the other numerical values gives $\mathrm{S}^{\prime}{ }_{20}$ of 860 Svedberg units for the visible boundary.

Quantitatively, the infectivity data can be interpreted in either of two ways. First it could be assumed that the virus particles all have the same size and sedimentation constant and that the visible boundary was not necessarily due to the virus. Then the infectivity data could be calculated to show that the sedimentation constant of the active virus falls within certain limits. In the present case it has been found convenient to express these limits as percentages of the sedimentation constant of the visible boundary, since the sedimentation rates of both the visible boundary and the infectivity varied markedly, but to the same degree, with the concentration of the extract which was centrifuged. Or, secondly, it could be assumed that the visible boundary was due to the active virus, in which case it

4The volume of water in the meniscus of a tube of this size is $1.023 \mathrm{~mm} . .^{3}$ (International Critical Tables, p. 7273). During centrifugation the gravitational force is increased sufficiently to make the surface nearly flat. Under these conditions the $1.023 \mathrm{~mm} .^{3}$ of water fills the whole tube a distance of $0.32 \mathrm{~mm}$., raising the point from which sedimentation starts by that amount. would mark the place of greatest change in virus concentration. The infectivity data could then be used to calculate the percentage of virus that has a sedimentation constant less than that of the boundary; in other words, to give some indication of the size range of the virus. If the infectivity data of the example under discussion are calculated on the assumption that all the virus has the same sedimentation rate and that the boundary is not necessarily connected with the virus, the result is obtained that the active virus has a sedimentation constant not less than 85 per cent nor more than 125 per cent that of the visible boundary. This follows from the fact that the virus must have been present at the point where the lower sample was removed. A particle sedimenting to this distance $\left(14.05 \mathrm{~cm}\right.$. from the center) would have an $\mathrm{S}^{\prime}{ }_{20}$ of 1075 Svedberg units or 125 per cent that of the boundary. Also, from past experience with the number of lesions obtained with different dilutions of the virus, it can be said that if the upper sample contained any virus, the amount was less than 10 per cent that of the lower sample. The virus, therefore, could not have been present at a point more than $0.5 \mathrm{~mm}$. $(0.1 \times 5 \mathrm{~mm}$. $)$ above the level where this sample was removed. In addition, there is a possible mixing error of about $0.5 \mathrm{~mm}$. during removal of the sample. A particle sedimenting to a distance $1 \mathrm{~mm}$. above the point where the upper sample was removed would have an $S_{20}^{\prime}$ of 730 Svedberg units or 85 per cent that of the visible boundary.

If the infectivity data are calculated on the assumption that the visible boundary marks the place of greatest change in virus concentration, it shows that not more than 10 per cent of the active virus has a sedimentation constant less than 90 per cent that of the boundary. For this calculation the infectivity data were interpreted as meaning that there was less than 10 per cent of the active virus small enough so that it had not sedimented past a point $2 \mathrm{~mm}$. above the visible boundary. This 10 per cent is a maximum value, for it was calculated on the assumption that the concentration of active virus did not measurably increase from the boundary to the point where the lower sample was removed. Actually, if the virus particles are not all the same size, the concentration should have increased in this region to an amount depending on the proportion of virus that sedimented faster than the visible boundary. The techniques used in the present experiments did not detect any such increase, for samples removed at various places below the boundary had approximately the same infectivity.

For electron microscopy (Wyckoff 1949) micro drops of suitably diluted suspensions were dried on the usual collodion-covered grids and then washed free from salts by the addition and subsequent removal of several droplets of water. After this they were dried, shadowed in the usual way 
TABLE 1. Sedimentation of infectivity of potato yellow-dwarf virus.

\begin{tabular}{|c|c|c|c|c|c|}
\hline \multirow[b]{2}{*}{$\begin{array}{l}\mathrm{S}_{20}^{\prime} \text { of visible boundary } \\
\times 10^{-13}\end{array}$} & \multicolumn{2}{|c|}{$\begin{array}{l}\text { Infectivity of samples removed } \\
\text { from centrifuge tubes }\end{array}$} & \multicolumn{2}{|c|}{$\begin{array}{l}\text { Limits of } \mathrm{S}_{20}^{\prime} \text { of virus } \\
(\% \text { that of visible boundary })^{a}\end{array}$} & \multirow[b]{2}{*}{$\begin{array}{l}\text { Measure of range of size of virus } \\
\text { particles }\end{array}$} \\
\hline & $\begin{array}{c}\text { Below } \\
\text { boundary }\end{array}$ & $\begin{array}{l}\text { Above } \\
\text { boundary }\end{array}$ & Upper & Lower & \\
\hline 892 & $1447 / 4^{d}$ & $0 / 4$ & 121 & 89 & 97 \\
\hline $785^{c}$ & $5000 / 5$ & $130 / 3$ & 120 & 89 & 95 \\
\hline $610^{c}$ & $397 / 2$ & $0 / 2$ & 126 & 67 & 75 \\
\hline $925^{c}$ & $453 / 2$ & $0 / 2$ & 117 & 79 & 84 \\
\hline $860^{c}$ & $900 / 2$ & $0 / 2$ & 125 & 85 & 90 \\
\hline $950^{\mathrm{c}}$ & $1720 / 2$ & $0 / 2$ & 122 & 86 & 91 \\
\hline $1070^{\circ}$ & $644 / 2$ & $0 / 2$ & 116 & 87 & 92 \\
\hline $1115^{c}$ & $174 / 2$ & $0 / 2$ & 137 & 85 & 93 \\
\hline
\end{tabular}

${ }^{a}$ Calculated from infectivity on the assumption that all the infective virus particles have the same sedimentation rate but that this rate is not the same as that of the visible boundary. Most significant values $=116 \%$ and $89 \%$.

${ }^{b}$ The figures represent sedimentation rates expressed as percentages of the sedimentation rate of the visible boundary. On the assumption that the visible boundary represents the virus, less than $10 \%$ of the virus can have sedimentation rates less than these. Most significant value $=97 \%$.

${ }^{c}$ Electron micrographs made from samples from above and below the boundary.

d Total lesions over total half leaves inoculated.

with either chromium or gold-manganin and examined under an RCA type EMU electron microscope. Most photographs were made at an original magnification of $c a 6000 \times$.

EXPERIMENTAL RESULTS.-Correlation of infectivity with boundary.-Sixteen sedimentation-rate experiments on eleven different virus preparations have been made. Those experiments in which infectivity tests were carried out are listed in table 1. Assuming that all the virus sediments at the same rate, columns four and five show the upper and lower limits of the apparent sedimentation constant of the active virus relative to that of the visible boundary. These limits were calculated as in the above example. The most significant figures are not the averages but rather those that show the narrowest limits, that is 89 per cent and 116 per cent. If the infectivity data are calculated on the assumption that the active virus may have a range of sizes, then not more than 10 per cent of the virus could have sedimentation rates less than the values expressed in column six, table 1 . Again the figure showing the narrowest limit is the most significant since the variation from experiment to experiment depends on the partly arbitrarily chosen points for removal of the samples. The absence of this boundary in preparations from healthy plants and the close association of the virus with the boundary as shown by these infectivity data, for all preparations tested and for a variety of experimental conditions, suggest that the boundary may be due to the virus. Hereafter, use of the term "sedimentation rate of the virus" will refer to that rate as measured by observation of this visible boundary.

In columns two and three of table 1 , the numerators give the number of lesions and the denominators give the number of half leaves inoculated with the samples removed from the centrifuge tubes. The infectivity found in the upper sample in one experiment could be interpreted as due to mixing during removal of the sample, which in this case was removed only $1 \mathrm{~mm}$. from the boundary, or as being a measure of the amount of virus with a slower sedimentation rate. If it is due to mixing, it would appear that $1 \mathrm{~mm}$. from the pipette intake is the approximate limit where mixing occurs during removal of samples by this technique. In most of the experiments the upper samples were removed $2 \mathrm{~mm}$. above the boundary, but in one case an upper sample was removed only $0.5 \mathrm{~mm}$. above the boundary and was not infective.

Correlation of bodies with infectivity and boundary.-Electron microscope mounts were prepared from samples removed from above and from below the boundary of the virus-containing tubes. Control samples were removed from tubes containing concentrates from healthy plants at positions corresponding to the lower samples from the viruscontaining tubes. These mounts were labeled in code and examined under the electron microscope by one of us who did not know the key to the code. Of eighteen electron microscope determinations on samples from below the boundaries in virus-containing tubes, fifteen were classified as having virus and three as doubtful. Of thirteen determinations on non-infective samples from above the boundaries in virus-containing tubes, seven were classified as having no virus and six as doubtful. Five determinations were made on mounts from the one infectious upper sample, mentioned earlier, and of these, two were classified as having virus and three as doubtful. Of twelve determinations on samples from healthy concentrates, eleven were classified as having no virus and one as doubtful.

Where the virus bodies predominate in a micro- 


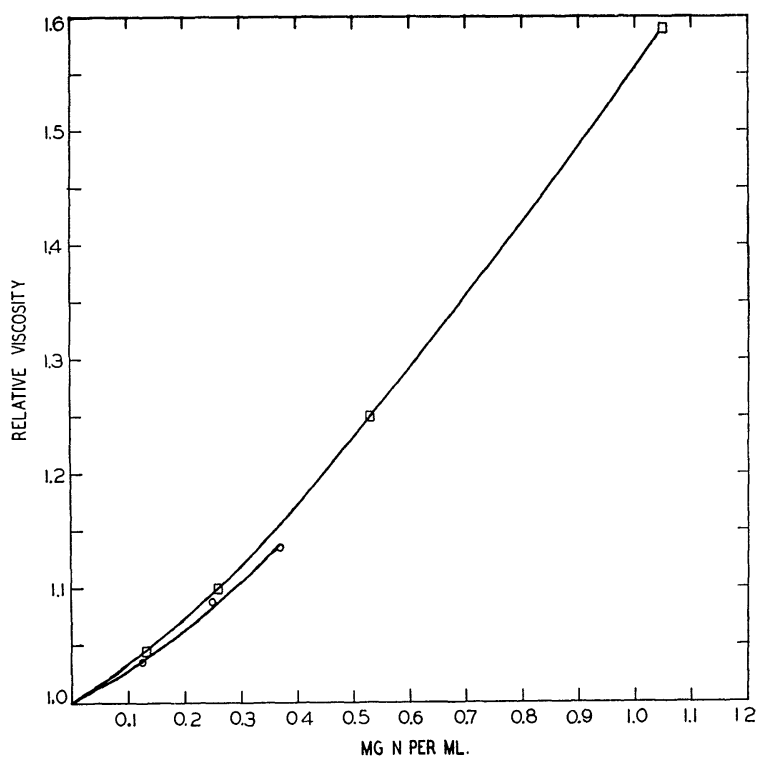

Fig. 2. Relative viscosity of two concentrates from healthy $N$. rustica prepared by two cycles of differential centrifugation.

graph, there is no difficulty in identifying them. However, some bodies seen in micrographs of concentrates from healthy plants are quite similar to the virus bodies. Of course, in concentrates from healthy plants there was no doubt that such bodies were not virus, but in preparations of origin unknown to the examiner, such cases were always classified as doubtful; it is likely that in most or all cases these bodies were not virus.

Variation of sedimentation rate with concentration.-In these impure preparations, the sedimentation rate of the virus varied markedly with the concentration of the extract. This may be explained by the high viscosity due to the impurities present. Fig. 2 shows the viscosities of two concentrates prepared from healthy $N$. rustica by a series of centrifugations such as were used to make the virus preparations. The concentration is expressed as milligrams of $\mathrm{N}$ per $\mathrm{ml}$. There were $18-20 \mathrm{mg}$. of solids per milligram $\mathrm{N}$ in these preparations. This viscosity is more than sufficient to account for the decrease in sedimentation rate of the virus with increase in concentration of the extract. However, it was impossible to make a direct correction of the sedimentation rate of the virus at any given total concentration of solids because the concentration of impurities was unknown, they were heterogeneous, and were sedimenting at various rates. The correct value of the sedimentation constant of the virus may be obtained by extrapolating to zero concentration.

Fig. 3 shows the apparent sedimentation constant of the virus plotted against the concentration of the extract expressed as milligrams $\mathrm{N}$ per milliliter. Each line represents a set of four values of $\mathrm{S}_{20}^{\prime}$ ob-

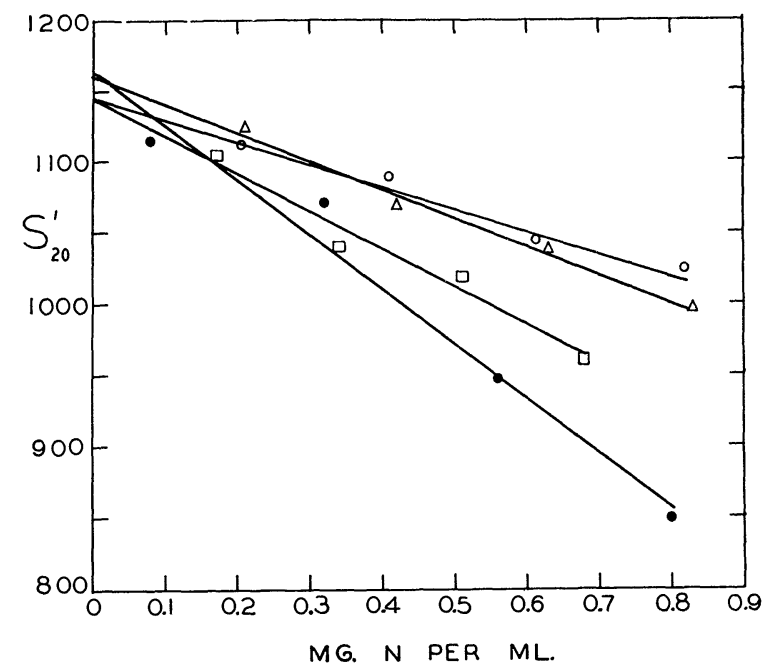

Fig. 3. The variation of the apparent sedimentation constant of potato yellow-dwarf virus with concentration of the extract. Each set of symbols represents a separate experiment.

tained by centrifuging four dilutions of one preparation of the virus. The lines were fitted to the points by the method of least squares. The slopes of the lines vary from preparation to preparation probably because no two of them had the same degree of purity nor did the impurities necessarily have the same composition or the same viscosity. This is illustrated by the difference in the viscosities of the two preparations from healthy plants shown in fig. 2. Despite the variations in slope, the extrapolated values are remarkably close. The sedimentation constant of potato yellow-dwarf virus is 1150 Svedberg units corrected to water at $20^{\circ} \mathrm{C}$.

In two experiments it was shown that the infectivity and bodies seen in electron micrographs follow the visible boundary in this variation of sedimentation rate with concentration. The marked variation of sedimentation rate of the virus with concentration of impurities makes it important to work with a relatively low concentration during purification of the virus by centrifugation. For the type of extracts used here, the concentration of solids should be less than $5 \mathrm{mg}$. per $\mathrm{ml}$. or the concentration of nitrogen less than $0.25 \mathrm{mg}$. per $\mathrm{ml}$.

Experience in obtaining the above results has given an indication of the accuracy of the method, which is important in considering its further use. The experimental error in any one value of $S_{20}^{\prime}$ is due mainly to three sources: (1) Measurement of the boundary. An error of $0.5 \mathrm{~mm}$. would cause an error in $\mathrm{S}_{20}$ of $c a$. 3 per cent. (2) Variation of temperature during the experiment. If the temperature averaged $1^{\circ} \mathrm{C}$. higher or lower than the final temperature, the error in $\mathrm{S}_{20}^{\prime}$ would be $c a .5$ per cent. (3) An error measuring the speed of rotation. The manufacturer claims an accuracy of \pm 25 r.p.m. for the tachometer. A variation twice 


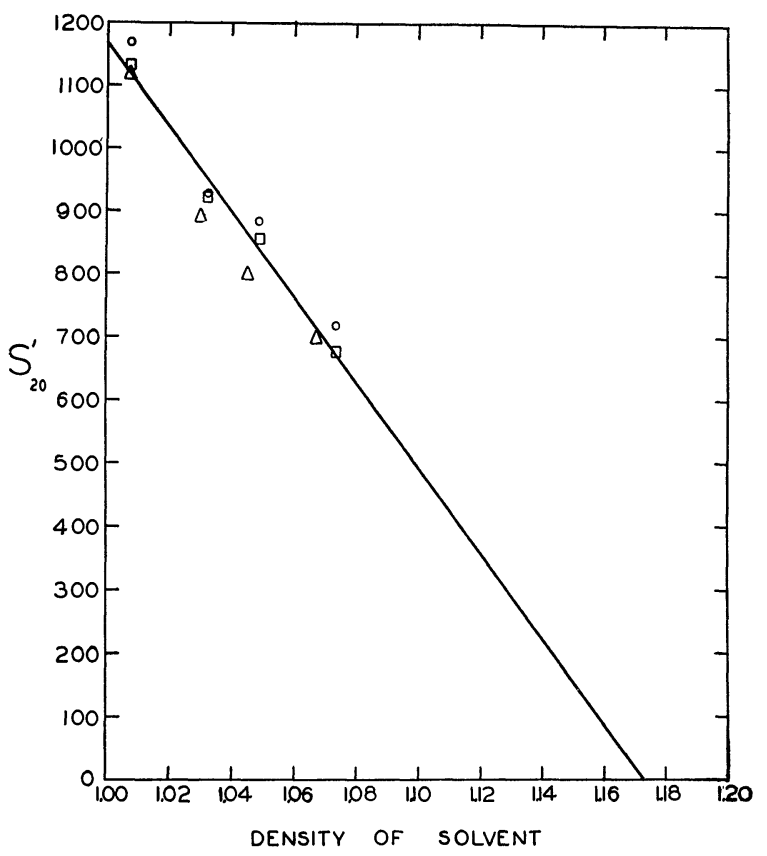

Fig. 4. The variation of the apparent sedimentation constant of potato yellow-dwarf virus with density of the sucrose solution used for solvent.

this great, i.e., 50 r.p.m., would cause less than a 2 per cent error in $\mathrm{S}_{20}^{\prime}$. The figures given for the first two sources are estimated to be the maximum error in any one value of $S^{\prime}{ }_{20}$ based on experience in reproducing the results from time to time. The reproducibility of the extrapolated result indicates that there is little error in it unless it is from some source that is consistently in the same direction.

Buoyancy experiments.-Three experiments were carried out on the sedimentation of potato yellowdwarf virus in sucrose solutions to obtain a measure of its hydrated density. This principle was first exploited by MacCallum and Oppenheimer (1922) and has since been used by several workers. For a review of the literature and interpretation of results, the reader may consult Lauffer, et al. (1949). Density and viscosity of the sucrose solutions were determined experimentally. After correction for viscosity, the sedimentation rate was plotted against the density of the solvent as in fig. 4. Extrapolation to zero sedimentation rate by the method of least squares indicates that the virus would not sediment in a solution of density 1.17. The hydrated density of the virus is therefore approximately 1.17. Because of the crudity of the apparatus used the result is not as accurate as desired. The data are not accurate enough to show whether the osmotic pressure of the sucrose solutions affected the density of the virus. The points on the graph were not obtained by extrapolating to zero concentration of nitrogen in the extract; however, the concentration was low so the error from this source is small.
Shape of the virus bodies. - The virus bodies as seen in the electron micrographs vary in shape from short rods to round types. In addition, some are much flatter than others. Fig. 5-12 show typical fields of preparations from both healthy and diseased plants. It may be noticed that some of the flatter types have a ring around them. This ring is seen only in virus bodies; it is never seen around bodies in preparations from healthy plants. The ring gives the appearance of a membrane that has collapsed to give a fold or has torn and slid off the central part of the body. Fig. 13-21 show bodies that appear to be intermediates between the various extremes of shape. Fig. 13-16 contain rods that have the ring. Fig. 17 shows a type intermediate between the rods and round forms. It gives the appearance of a rod, one end of which has collapsed and spread out. Fig. 17-21 show bodies that have the ring around only part of their circumferences. They appear as if the membrane had torn in such a way as to slide off only part of the body. This gives evidence that bodies with and without the ring are both virus; it also strengthens the implication that this ring is due to a membrane. Similar membranes are readily discernible around the elementary bodies of psittacosis and other large animal viruses as well as about phage particles (see electron micrographs accompanying Chapter VIII of Wyckoff, op. cit.).

This membrane and other features of the structure may be seen more clearly in the drawings of fig. 22. Drawings numbered 13-21 are of bodies from the corresponding figures. Drawing 22 is of two overlapped rod-like bodies from A in fig. 9. Fig. 23 shows an electron micrograph of a field of potato yellow-dwarf virus at higher magnification. At this magnification the irregular shape of the bodies is readily seen. Drawing 23 of fig. 22 represents one of these bodies of irregular shape (the body at $\mathrm{A}$ in the figure).

The cause of this variation in shape is not known. It should be pointed out, however, that these variations in shape are of the same general sort as may be seen in electron micrographs of different cultures of the same microorganism (Shepard and Wyckoff, 1946). The treatment during electron micrography seems to be partly responsible because bodies on any one screen are often quite uniform in shape and apparent size while bodies on different screens of the same sample may vary considerably. Fig. 7 and 8 show micrographs of two mounts prepared at the same time from the same sample of the virus. It is seen that in one case the bodies are flat and have the ring while in the other they stand up better and do not have the ring.

In the first published photographs of potato yellow-dwarf virus (Black et al., 1948) the virus bodies were all rod shaped. In the present series of experiments the virus usually appeared as a round form though some rods were present. At one time 


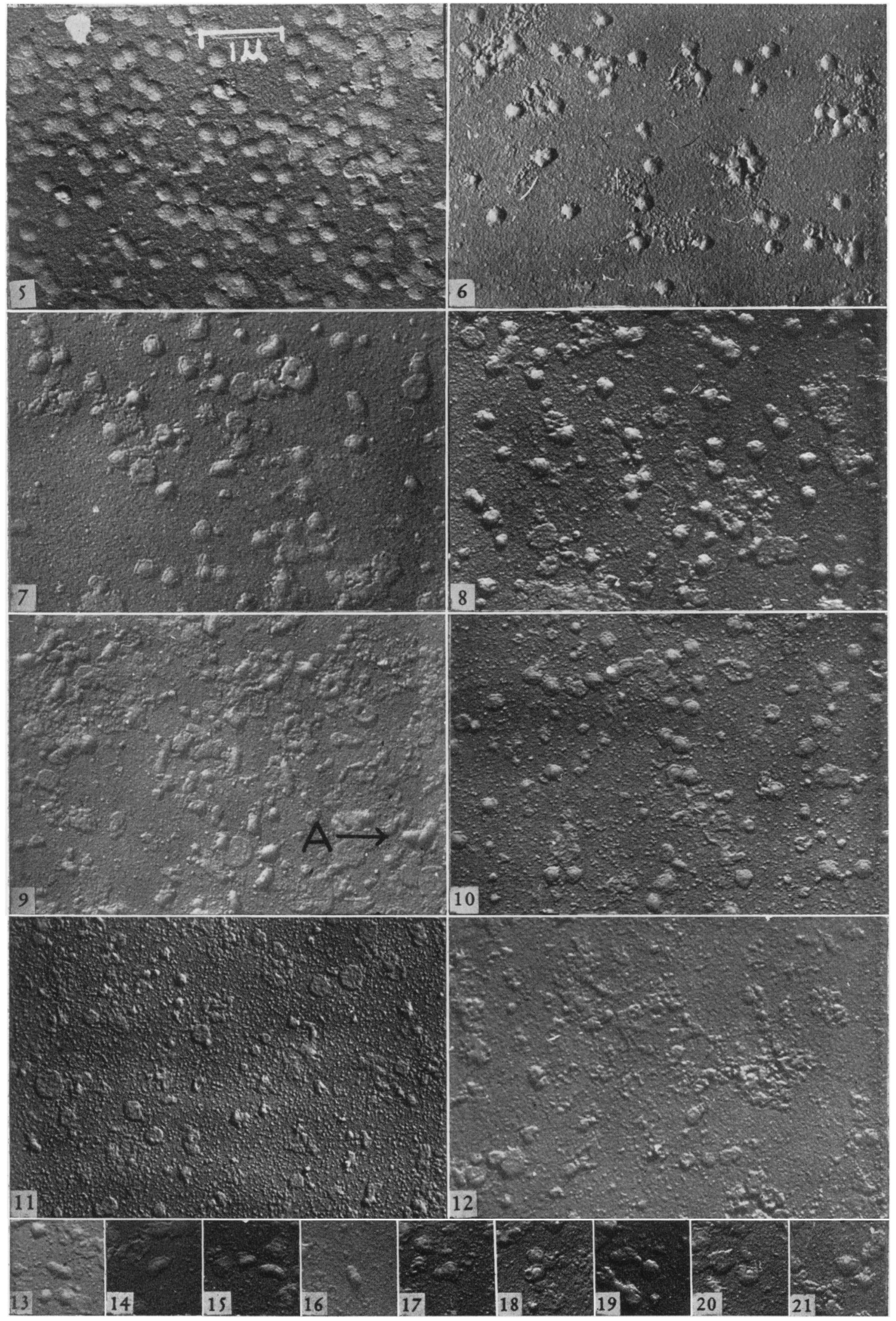



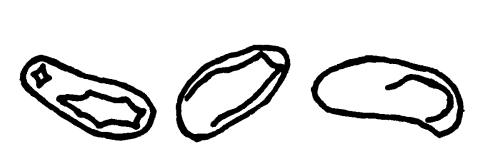

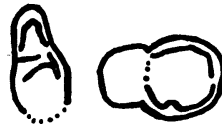

16

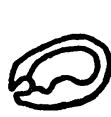

18

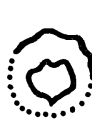

19

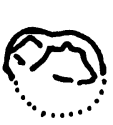

20

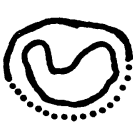

21

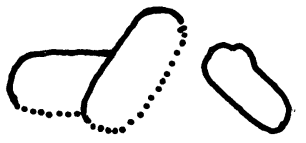

22

Fig. 22. Drawings of some virus bodies of potato yellow-dwarf. Drawings 13-21 are of bodies in the corresponding figures. Drawing 22 is of two overlapped rod-like bodies from fig. 9 at A. Drawing 23 represents an irregular virus body (A) from fig. 23.

pictures were obtained, as in fig. 9, that were very similar to those published by Black et al. (1948). This particular concentrate was prepared by adding formaldehyde a few hours after the leaves were ground. However, this procedure did not always result in concentrates that gave pictures with a high proportion of rods.

The appearance of the virus particles with a round or rod shape in electron micrographs may reflect the variability in the shape of this virus.

Discussion.-The main advantage of the above method for the determination of sedimentation constants is the ease with which biological or chemical activity can be used as the criterion for the presence of the desired entity. The preparation needs only to be concentrated enough so that the entity in question can be detected in a small sample. A quantitative assay is not needed, a qualitative one suffices. If the assay is sufficiently sensitive, the centrifugation can be carried out at a concentration low enough to make the effect of impurities negligible. This concentration will vary from case to case and should be determined for each type of preparation. For large particles with sedimentation constants above 200 or 300 Svedberg units, the simple equipment used in the present experiments may be used. The fact that several tubes can be used at once makes it possible to get several values so that some of the random errors cancel each other. Refinements in this technique should permit more precise measurements.

The diameter of the hydrated virus, as calculated from the sedimentation constant and using a value of 1.17 for the hydrated density, is $110 m \mu$., the volume $690 \times 10^{3} \mathrm{~m} \mu$., and the "particle weight" is $490 \times 10^{6}$. In these calculations the virus was assumed to be spherical and to follow Stokes' law. The virus bodies seen in the electron micrographs vary in diameter from 120-290 $\mathrm{m \mu}$. and in height up to $50 \mathrm{~m} \mu$. with most being less than $30 \mathrm{~m} \mu$. In many fields, the bodies were so flat that they had no shadow or one falling only from their edges. In such cases, it was impossible to make a reasonably accurate estimate of their heights. To get as good a value as possible of the size of the virus bodies. from the electron micrographs, four fields were selected in which the bodies had good shadows (as in fig. 23) and all the isolated virus bodies on these fields were measured. The histogram shown in fig. 24. represents the number of bodies found in each range of volumes. In calculating these sizes the virus bodies were assumed to have the shape of half an oblate ellipsoid. A close inspection shows that this is not strictly true for most of them have irregular contours. In addition to the error caused by this irregular shape, there is an error in the linear measurements of nearly 10 per cent which could not be avoided because of the limited resolution on further magnification. Since the volume is a cubic measurement, this could lead to an error in the volume of almost 30 per cent. Theoretically this error should have been random, but actually it was not, as was shown by analysis of the measurements. In making the measurements, it was necessary to estimate the second significant figure. The analysis demonstrated that in making these estimates the experimenter had an unconscious preference for estimating figures that were multiples of five. This led to the bimodal distribution of volumes seen in fig. 24. It may also have made the, measured average volume larger or smaller than the actual average volume.

The volume of the virus as obtained from the electron micrographs is larger than the value obtained from the sedimentation constant despite the fact the former value refers to the volume of the dry virus while the latter refers to that of the hydrated virus. However, the discrepancy is not serious for it may be due to the errors made in the measurements on the electron micrographs and to the probability that the assumption made in calculating size from these measurements and from the sedimentation constant do not strictly hold.

There is one error in calculating size from the electron micrographs that leads to a consistent overestimate of size. This error arises from the fact

Fig. 5-21. Fields from electron micrographs of concentrates from $N$. rustica-Fig. 5, 6. Two different concentrates from: yellow-dwarf $N$. rustica, both of which had stood for several days at $0^{\circ} \mathrm{C}$. Note the contrasting degree of flatness. - Fig. 7, 8. Fields from two different screens of the same sample mounted at the same time. Note difference in degree of flatness.-Fig. 9. A field showing the virus bodies largely as rods.-Fig. 10. A field in which the virus bodies have the characteristic ring.-Fig. 13-16. In the center of each of these is a rod-shaped virus body with a ring around part or all of the body.-Fig. 17. A virus brody that is intermediate between the rod-like and round types.-Fig. 18-21. Round virus. bodies that have the characteristic ring about only part of their circumference and with a line over the top of the body. -Fig. 11-12. Fields of two different concentrates from healthy $N$. rustica. 


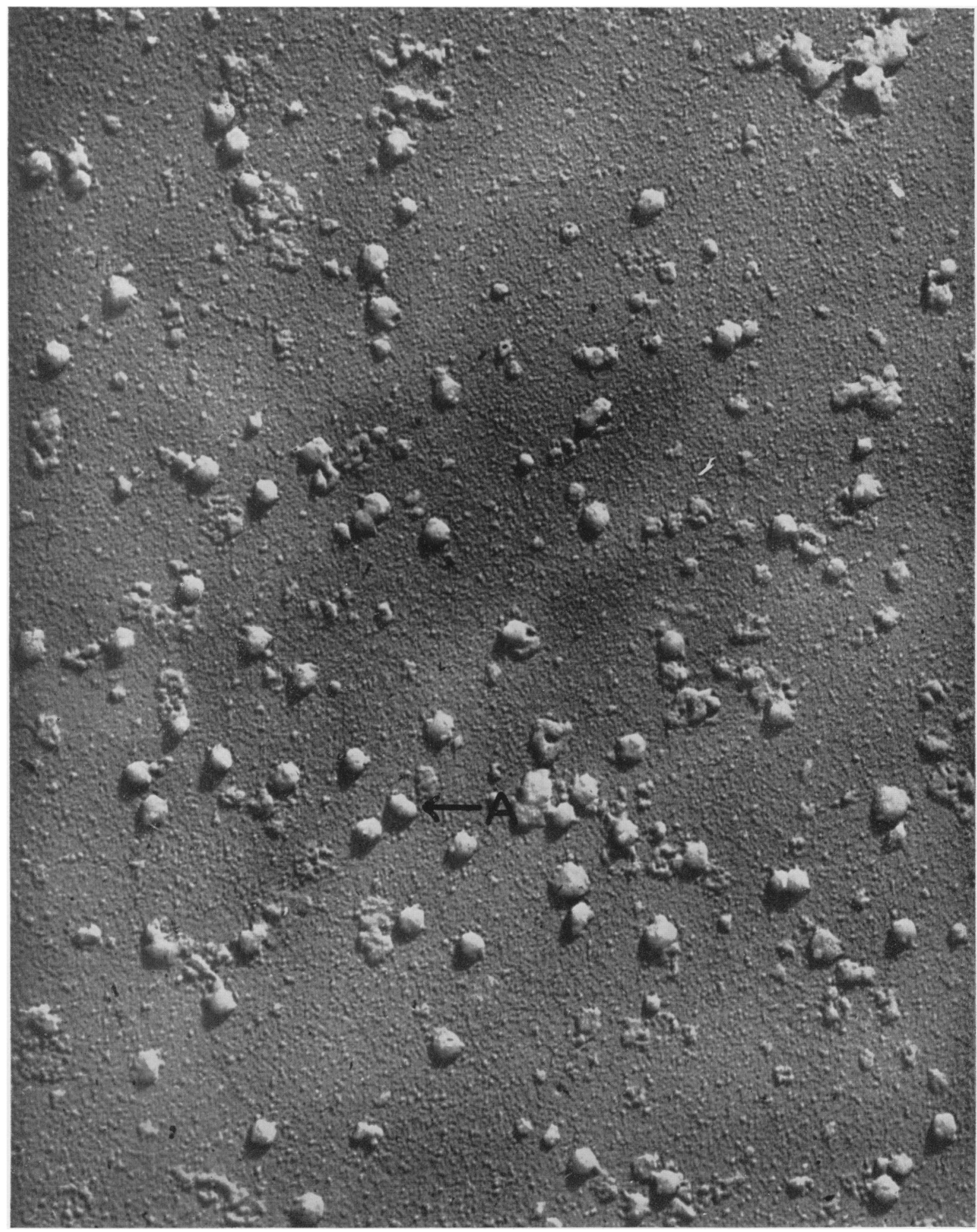

Fig. 23. A field from an electron micrograph of potato yellow-dwarf virus, magnification about $22,000 \times$.

that the furthest point of the shadow is cast not by the top of the body but rather from a point where the path of the shadowing particles is tangential to the surface of the body. Measurement of the shad- ow length from this point leads to an underestimation of the height; measurement of the shadow length from the center of the body leads to an overestimation of its height. Since it is difficult to 
tell the exact point where the densest shadow begins, measurements of shadow length in the present case were made from the center of the bodies. For bodies with the shape of half an oblate ellipsoid, this leads to an error of 3 per cent if the height of the body is equal to the radius; i.e., for the special case of a hemisphere. However, as the bodies become flatter the error becomes progressively greater. Thus, when the height is half the radius, it is estimated at 112 per cent of its true value and when the height is one-fourth the radius, it is estimated at 142 per cent of its true value. The potato yellowdwarf virus bodies are too irregular in shape for this correction to be accurately applied. The bodies measured for the results given in fig. 24, had heights approximately half their radii, and their calculated volumes are therefore about 12 per cent too high.

The measurements reported in fig. 24 give an erroneous impression in another respect, i.e., concerning the size distribution of the bodies. As mentioned above, errors in the linear measurements were not random and led to a larger number of bodies at the ends of the distribution curve than there should have been. The infectivity data, when calculated as the proportion of active virus with a sedimentation rate less than that of the boundary (column six of table 1), give evidence that there is less virus at the small end of the size distribution range than indicated by fig. 24. The two sets of values are not directly comparable since the sedimentation rate is proportional to the square of the radius while the volume is proportional to the cube of the radius. If the size distribution curve is symmetrical, there should also be a rapid falling off in the number of bodies as the size increases above that of the bodies in the boundary. The bodies in micrographs of mounts prepared from samples removed from below the boundary showed at least as great a variation in apparent size as the range reported in fig. 24 and yet these bodies, by the very fact that they were removed from a short distance in the tube, could not have had a size distribution greater than about 30 per cent. It must be concluded that the size distribution indicated in fig. 24 is incorrect, caused in part by error in measurement and in part by the fact that a real variation in shape causes an apparent variation in calculated size.

The hydrated density as determined above (1.17) may not be absolutely identical with the density of the virus as it exists in the plant cell or in dilute solutions. However, it is useful for comparison with similar values for other plant viruses determined by the same method. Schachman and Lauffer (1949) found a value of 1.27 for tobacco mosaic virus and Taylor and Lauffer (1949) found a value of 1.25 for southern bean mosaic virus. This indicates that potato yellow-dwarf virus is either more highly hydrated than these two or else has a lower anhydrous density. A high hydration would be consistent with both this low hydrated density and the variation in shape of the bodies seen in the electron micrographs.

The potato yellow-dwarf virus appears to be quite different from other plant viruses previously investigated in these particulars. Its large size, low density, variable shape in electron micrography, and the suggestion of a membrane seen in some electron micrographs all are properties that distinguish this virus from those previously described. These properties are consistent with the conception that it may be a microorganism.

\section{SUMMARY}

Preparations made by differential centrifugation of juice from Nicotiana rustica L. infected with potato yellow-dwarf virus showed a visible boundary after horizontal centrifugation in a $2 \mathrm{~mm}$. capillary tube at 3400 r.p.m. Similar preparations from healthy plants showed no such boundary. The sedimentation constant at infinite dilution of this boundary is 1150 Svedberg units. Samples removed from above this boundary are not infective nor do they contain virus bodies as seen in the electron microscope. Samples removed from below the boundary are infective and when examined under the electron microscope show the virus bodies. Quantitatively the infectivity data show that the sedimentation rate of the virus cannot be less than 89 per cent nor more than 116 per cent that of the visible boundary. Buoyancy experiments with sucrose solutions indicate that the virus had a hydrated density of approximately 1.17. The virus as seen in electron micrographs shows considerable variation in shape. Making certain assumptions, including a spherical shape for the virus, its diameter has been

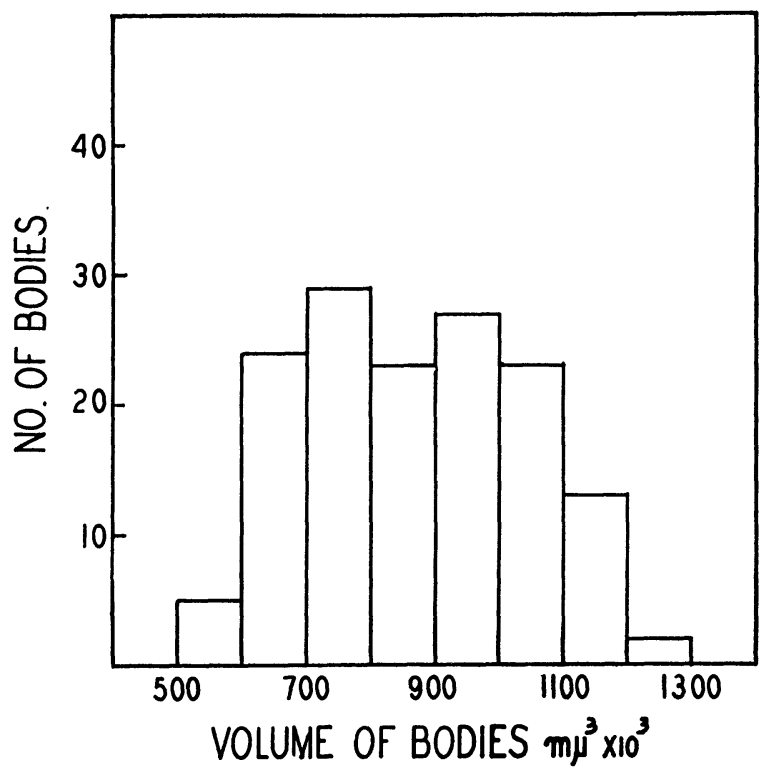

Fig. 24. Results of measurements of all isolated bodies of fig. 23 and three other fields of the same concentrate. The histogram gives the number of bodies actually found in each size range: 
estimated at $110 m \mu$. from the sedimentation constant. The range of volumes of the virus particles seen in electron micrographs has been estimated and plotted. The volume of a particle $110 \mathrm{~m} \mu$. in diameter falls within this range.

The Brooklyn Botanic Garden, BROOKLYN 25, NEW YORK AND

Laboratory of Physical Biology, National Institutes of Health, Bethesda, Maryland

\section{LITERATURE CITED}

Black, L. M. 1938. Properties of the potato yellow-dwarf virus. Phytopath. 28: 863-874.

- 1951. Further studies on the properties of potato yellow-dwarf virus. Phytopath. 41:213-220. , V. M. Mosley, and R. W. G. Wyckoff. 1948. Electron microscopy of potato yellow-dwarf virus. Biochim. Biophys. Acta 2: 121-123.

Brakke, M. K., L. M. Black, and R. W. G. Wyckoff, 1950. Correlation of potato yellow-dwarf virus bodies with infectivity during centrifugation. Phytopath. 40: 3.

Elford, W. J. 1936. Centrifugation studies: I. Critical examination of a new method as applied to the sedimentation of bacteria, bacteriophages and proteins. Jour. Exp. Path. 17: 399.
Holmes, F. O. 1948. The filterable viruses. Supplement No. 2. Bergey's Manual of determinative bacteriology. p. 1155. The Williams and Wilkins Co., Baltimore.

International Critical Tables. 1926. Published for the National Research Council by the McGraw-Hill Bock Co., Inc., New York.

Lauffer, M. A., W. C. Price, and A. W. Petre. 1949. Advances in enzymology. Vol. 9, p. 171-240. Interscience Publishers, Inc., New York.

MacCallum, W. G., and Ella Hutzler Oppenheimer. 1922. Differential centrifugalization: a method for the study of filterable viruses as applied to vaccinia. Jour. Amer. Med. Assoc. 78: 410.

McIntosh, J., and F. R. Selbie. 1937. The measurement of the size of viruses by high-speed centrifugation. Jour. Exp. Path. 18: 162.

Schachman, M. K., and M. A. Lauffer. 1949. The hydration, size and shape of tobacco mosaic virus. Jour. Amer. Chem. Soc. 71: 536-541.

Shepard, C. C., ANd R. W. G. Wyckoff. 1946. The nature of the soluble antigen from typhus rickettsiae. Public Health Reports 61: 761-767.

Svedberg, T., And K. O. Pedersen. 1940. The ultracentrifuge. The Clarendon Press. Oxford.

TaYlor, N. W., AND M. A. Lauffer. 1949. Hydration of southern bean mosaic virus. Amer. Chem. Soc. 116th Meeting, Atlantic City, N. J. 1949. Abstracts of paper. p. 18C.

Wyckoff, R. W. G. 1949. Electron microscopy, technique and applications. Interscience Publishers, N. Y. 